\title{
ON THE RELATIONSHIP BETWEEN GEOSYSTEMIC SELF- ORGANIZATION AND SPATIAL PLANNING
}

DOI: http://dx.doi.org/10.18509/GBP.2015.21

UDC: 007:004]:528

\author{
Assoc. Prof. Dr. Vasile Zotic \\ Dr. Diana-Elena Alexandru \\ Babeș-Bolyai University, Centre for Research on Settlements and Urbanism, Cluj-Napoca, \\ Romania
}

\begin{abstract}
The aim of this study is to argue for the existence and acknowledgement of an implicit relationship between geosystemic self-organization and spatial planning. This one-way relationship should develop as correspondence and subordination for the harmonious integration of sociosystems into the geosystems. Based on the role and influence of selforganization, and the fact the sociosystemic organization is tributary to the geosystemic organization under any circumstances, we formulate several significant guidelines for better future urban and rural territorial design, to avoid disturbances in the geographical space that would trigger coercive adjustments of other components. Thus, we bring forward the fundamental idea of functional integration of planning and self-organization to guarantee the harmonious integration of man-made structures into the geosystem and assure the permanence of humanity in the next future.
\end{abstract}

Keywords: self-organization, spatial planning, geosystem, functional integration

\section{INTRODUCTION}

Understanding the organization of geographical space and of geosystems represents the ultimate premise to properly implement the necessary planning measures and achieve sustainable development. This prerequisite must be perceived and understood from two perspectives. Firstly, geographical space and self-organized natural geosystems represent the foundation (space and framework) for the development of the sociosystems. Hence, based on technology, planners should make alterations to these natural structures up to their tolerance level, not disregarding the spatial organization patterns and causing adverse reactions and disequilibrium in their organization. Secondly, sociosystems and their structures are entirely dependent on the geosystems' available resources, which set their development level along with technology and quality of human resources. Thus, to accomplish suitable and right spatial planning we must consider geographical space and its geosystems, either global or local, as a complex reality and as the only available environment for the actual and future existence and development of human civilization.

\section{SPATIAL PLANNING THROUGH GEOSYSTEMIC SELF-ORGANIZATION}

The multifaceted relation between self-organization of geosystems and spatial planning has been subject of discussion for numerous researchers all of them emphasizing on the complexity of natural systems and man-made systems in their functional organization (Allen, 1997; Portugali, 1999; Zotic, 2005; Pulselli and Tiezzi, 2009; Boonstra and Boelens, 2011; Hua, 2012; Alexander, Mazza and Moroni, 2012; Barthelemy et al. 2013; 
Goleusov, 2014) and arguing for a new perspective on spatial planning. Hua (2012) stated there are two primary problems about self-organization that planners should consider: how it works and how to utilize it [1]. Planning should not be external and independent of the autogenic quality of the geosystems intrusively affected by the urban systems, which have their own capacity to evolve as complex self-organized phenomena [2][3]. Self-organization can also be employed to regenerate the geosystems degraded by human intensive exploitation actions. Thus, knowing the restructuring time of geosystems through their capacity to self-organize we could include them in the category of geosystems at rest to give them time to regenerate [4]. Spatial planning should take account of the specifics of the geosystems, since they have most profound impacts on the functioning of the newly-designed sociosystems, either stabilizing or shaking their foundation in time. Thus, sociosystems become add-ons to the geosystems. The more unawarely planning and decision-making, the higher are the chances to disrupt the natural system, this proving again the interdependency relations between nature and the emergence and design of sociosystems. Then, we can infer that the ultimate purpose of spatial planning and territorial development is to create favourable conditions for the development of man-made dissipative systems. Zotic (2005) proposed two ways to achieve this: either through intense dissipation of energy or through rational dissipation of energy [5, pp. 27-29].

i) the intense, continuously increasing dissipation of energy, while not adapted to the real available capacity of energy flow at a time or for a certain period of time, entails the "rapid erosion" of the available energy potential. Geosystems reach the "lack of energy" state, eventually requiring extensive structural reorganization or even their dismantlement. This type of planning would inevitably lead to excessive energy consumption through dissipation of energy taken from other flows or from dismantling other geosystems. Or, it would create oversized geosystems, some purely technogenic, not being the result of an evolutive process (thus vulnerable to changes in threshold limit values). They would have growing dissipative capacity, high consumption level on short periods of time without producing satisfactory evolutionary mutations to adapt to the new conditions. Also, in the dissipative process this type of geosystems would generate an increasingly large amount of positive entropy, which lower-ranked geosystems would not be able to assimilate, fact that would cause choking in their own positive entropy $5 \mathrm{p}$. 28]. This kind of behavior corresponds to the provisions of the second law of thermodynamics, yet creating the prerequisites for spontaneous or accelerated energy dissipation, which is specific to inorganic geosystems. This inevitably leads to the disappearance of these geosystems once they reach thermodynamic equilibrium. Since man first appeared in the geographical space as biological being and afterwards as a social being, by going through all evolution stages, there has been no second chance for such biological entities to occur. They evolutionarily self-reproduce and do not spontaneously organize. In conclusion, we should avoid this direction in development and planning, as it is damaging and only momentarily effective, while progressively inducing social and territorial chaos.

ii). the rational dissipation of energy, adapted to the real available capacity of energy flow allows the geosystems to longer survive with minor adaptive structural modifications, depending only on the energy flow fluctuations and on the competition against other dissipative geosystems and sociosystems. This type of behavior is part of the wider actions of spatial planning, in which case sociosystems would fit into geosystems. Geosystems that are not allowed or are conditioned to run dissipative functions are 
doomed to disorganize, which entails disturbances in the energy flow of the geographical space and imposes rehabilitation processes from other components under coercive circumstances. First, this means avoiding to take over a larger amount of energy from the natural flow than the lower energy tolerance threshold of geosystems, which would provide an opportunity for optimal functioning (energy dissipation) and their very existence, and secondly, to streamline the energy dissipation by sociosystems in accordance with the limited availability of "free" energy. Spatial planning and development are directly dependent on the amount and quality of resources and energy potential of the geographical space. To meet the needs of dissipation, the energy deficit is substituted by import while the surplus is managed by storage (natural or technogenic) and export (the dynamics of matter that carries the energy flow in the direction of the minimum gradient potential corresponding to the energy deficient area). The amount of energy entering a geosystem represents the degree to which it was removed from equilibrium, measured by its gradients, which it would have to annihilate by dissipation to return to its original state. Once a geosystem enters disequilibrium, it will certainly try to counter the applied energy gradients. If energy gradients applied to the geosystem grow, then its "capacity" to resist the disequilibrium will increase. The very organization diversity of the current human civilization represents the diversity of energy dissipation patterns and forms of distancing or getting closer to thermodynamic equilibrium. In the case of self-organized geosystems, countering the applied gradients persists to a certain critical lower level (minimum energy level specific to the existence of the geosystem), when the dissipative process is reduced to the maximum possible, and the geosystem enters the stage of energy deficiency. Reaching this minimum level determines the onset of some reactions (i.e. firstly negative and then positive feedback) to obtain new amounts of energy. After ruling out all options and it proves impossible, the system falls below the lowest energy tolerance, disorganizes and disintegrates, releasing the minimum energy available from the components as "free" energy in the environment. We can then deduct that the emergence and existence of (geo)systemic structures is possible only outside thermodynamic equilibrium, when various-level organizational structures appear by the cooperation of components to facilitate and streamline energy dissipation. In case of thermodynamic equilibrium, reached only in total isolation, once the components of the systemic structure dissipate the available energy (negative entropy), they go back to the state of complete chaos (positive entropy) and the systemic relations disappear. Thus, if there is external or internal available energy of a certain intensity, which acts as an attractor, it determines matter to organize in systemic structures to dissipate that energy. This plea for demonstrating the significance of self-organization in spatial planning has no other purpose than that to seriously warn us to carefully observe everything that happens around us. It would be wrong to implicitly further accept this permanent and seemingly limitless brutal interference of man in the organization of geographical space, by still pretending the lack of knowledge on these realities. We need to stop following temporary interests without having an integrated and responsible vision of everything we create and accomplish. The paradigmatic sense of the future spatial planning should be organic, fitted into the parameters of availability provided by the geographic areas, supple and easily adaptable to the changes imposed by the geosystemic self-organization. Sociosystemic organization is dependent on the geosystemic organization under any circumstances. The age of waste must cease and the design of development should be integrated into the coordinates of organic development. 
In opposition to the geosystemic self-organization, which is fully coordinated by natural laws, spatial planning has now become a social activity conducted by national/local bodies to provide and define the future development actions society must undertake to ensure space-time sustainability.

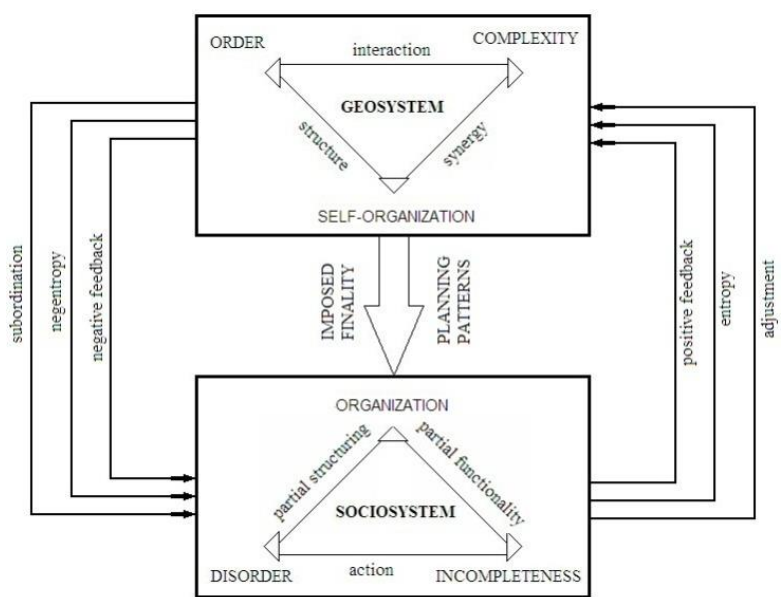

Fig. 1. Relationship between self-organization and planning

This activity is permanent but also strongly affected by the lack of real time information on the status of geosystemic self-organization and by the designers' inability to see clearly enough all issues as a whole. Moreover, there has been a strong political interference in spatial planning, which turned it into a governance tool. This further contaminates the quality of planning knowing that politics follows more the group interest and less the interest of masses and society as a whole. Thus, we come to witness huge discrepancies between the theory of planning and the reality of planning, consisting in rather mere facilities established to ensure the functionality of sociosystems and not their organic integration into the geosystems. Subsequently, strategic planning for sociosystem development is still inconsistent, being able to speak of rather incipient actions providing possible development directions that no one can follow, and not anchored thoroughly and completely with the self-organization of geosystems.

\section{ROLE AND IMPLICATIONS OF GEOSYSTEMIC SELF-ORGANIZATION IN SPATIAL PLANNING}

The truth is that spatial planning would be almost impossible if neglecting almost all the information on self-organization and not sufficiently valuing this knowledge. Currently, spatial planning is done rather independently from self-organization and not integrated into it. What should be done? The solution is to go back to nature and learn to know it by careful observation, learn to "cultivate" the sun and the wind instead of energy crops thus destroying the soil, learn to wait for nature and not hurry and constrain it for ephemeral advantages. The current planning paradigm is in need of a change and it should be directed towards natural organic integration. The role and general implications geosystemic self-organization has in spatial planning can be grasped from several general guidelines that must be considered in the planning process. To this end we defined the following geosystemic self-organization-related guidelines that we consider most important and which would lead to a shift from the current development paradigm to the organic integration paradigm:

1). Geosystemic self-organization directs and determines the location of human activities. This is the first condition that (geo)structures impose to man-made structures in their organization and development planning. This challenge arises from the fact that due to their self-organization particulars not every (geo)structure is suitable to any socioeconomic activities, being restrictive for some anthropogenic uses. Hence, we could define a new principle - The principle of consistency between self-organized geo(structures) and planned man-made structures. Accordingly, all forms of spatial development and planning would 
be linked and adapted to self-organized geo(structures) to maximize benefits in land management and minimize risk factors, which are nothing but feedbacks to the ignorance of this principle. Thus, the first step in spatial planning is to thoroughly analyze (geo)structures and define their operating parameters, which are the expression of their selforganization mode. After considering these operating parameters, the anthropogenic structures (technical, economic, social) may be designed.

2). It limits or favors economic land exploitation causing variable investment costs. The specifics of self-organized geosystems (limited spatial extent, impact tolerance values and sensitivity to the threshold effect, capacities and speed of regeneration) are acting as restrictive factors. Alternatively, spatially extended geosystems, with high tolerance to impact and low sensitivity to threshold effect, capacity and high speed of regeneration are favoring socioeconomic exploitation. However, regardless of their nature and spatial dimensions, all geosystems are finite and hence, limited tolerance, sensitivity, capacity and speed that imply cautious and aware exploitation and planning.

3). It provides society with natural self-organized structures that man uses to create anthropogenic structures on. Natural self-organizing structures have such an advanced order and low entropy that it becomes the most valuable asset humanity has in their development process. This derives from the inseparable connection between nature and society, the latter being the evolving product of the first, created in accordance to nature's self-organization patterns. Thus, society cannot avoid, deviate from or abandon the selforganized structures, being required to integrate harmoniously within them to survive and evolve to the maximum.

4). It shapes and influences the spatial configuration and structure of human territorial systems. Regardless of scale (macroscale, mesoscale or microscale) the configuration of self-organized geosystems is limited both as structure and as spatial extension, always having a self-sufficient organized structure under certain environmental conditions. In this context, geosystems determine the configuration and structure of human systems at a minimal organization level and influence the maximum organization level. If the minimax principle prevails in spatial planning, then we can admit the influence of geosystems on the configuration and structure of sociosystems.

5). It stimulates planners to identify new technical solutions for the optimization of manmade systems, to adapt to the self-organization of geosystems. Self-organized geosystems are constantly in a dynamic equilibrium in response to changing environmental conditions and free energy flow that permanently transits them. This entails permanent adjustment of their internal parameters of state, structure, configuration, time and spatial extent. Hence, anthropogenic systems are constantly forced to adapt to the new features of geosystems through optimization, adoption of new technical solutions and constant design readjustment. All these prove necessary, although it is almost impossible to accurately forecast the future self-organization of geosystems.

6). It implies fair exploitation. Geosystems are complex self-organized structures of different tolerance capacity to impact. This capacity is not infinite and is constantly changing along with the parameters that determine the self-organization. Man and society should maintain the exploitation of geosystems within its tolerance limits, defined by threshold limit values, in which limits the sensitivity triggering informational feedback does not activate so as the geosystem should readjust to a lower level of self-organization or even dismantle. This balanced exploitation of geosystems should be dynamic and the used techniques must be adjustable in intensity in accordance with the variation of the parameters. 
7). It provides location and functional advantages but also structural disadvantages. Geosystemic self-organization pattern can provide planners with essential data, which helps them decide where to locate man-made structures to further grant lower costs for investment, operation and maintenance. In contrast, geosystemic structure and function may require the implementation of simplified anthropogenic structures. If not considered, planners could generate complex anthropogenic structures, highly costly and difficult to manage. Since all human systems have no self-organization properties than to a lesser extent, the more complex a system, the more difficult and expensive the coordination and exploitation become. Hence, it is indicated that anthropogenic structures should be simplified to the maximum extent.

8). It requires the man-made structures to be size-adapted in volume, structure and functionality. The complex and dynamic nature of geosystemic self-organization according to their own laws, which cannot be influenced by man and society, requires the constant adaption of anthropogenic structures to the basic functional parameters of natural structures in size, structure and functionality, as a prerequisite for the sustainable territorial development. Failing to follow these functional parameters, hence exaggerating volume, structure to functionality up to inadequacy would necessarily activate the sensitivity triggering feedback reactions with unpredictable and especially hardly manageable effects. Thus, we can define a new principle in spatial planning - The principle of adaptability of anthropogenic structures to natural structures.

9). It generates adverse effects when tolerance limits of self-organized structures are exceeded. This is part of geosystems' behavior in specific situations when their tolerance level is overcome, thus leading to feedback reactions of different intensities and temporal and spatial expression. In case of extensive anthropogenic impact overlapping the permanent stress factors of the geosystem results can be disastrous, up to the disintegration of the geosystem, with effects and repercussions difficult to quantify. Accordingly, spatial planning must promote operational and coordination policies complying with the rule of "subtle" coordination of natural systems [6].

10). It can act regeneratively on the (geo)structures affected by human activity. The regenerative properties of self-organization can be seen as ways and solutions to counteract the applied anthropogenic pressure so as to stabilize the geosystem on the same organization hierarchy level, but they can also be the advantage offered by geosystems to artificial structures in case of tolerable interferences. Thus, if properly understood and managed reasonably, the geosystemic regenerative capacity can support the harmonious integration of human structures through long-term planning and exploitation of natural structures.

11). It determines temporality (lifespan) and rhythm in organizing the man-made structures. Temporality is an inherent and particular property of the internal selforganization of each geosystem. Thus, we can note geosystems of annual, secular, millennial or greater temporality. In contrast, the lifespan of geosystems is finite in case of a given set of self-organization parameters (extension, structure and functionality). Limitation and internal temporality of geosystems further configures the organization temporality and rhythm of human structures that can avoid it only to a small extent.

12). It generates economic resources. The very order of the geographical space is a resource, which man and society still have not learned to properly value and manage. This order was the primary premise for the appearance of man as social being and of civilizations that succeeded in time, most often as expressions of this order. And now, this spatial order, which can hardly be maintained through permanent regeneration, 
represents the foundation of social and territorial organization. Therefore, we should only understand and apply this order in planning, adapt anthropogenic structures to it and learn what organization is from nature embracing the principle "Nature knows best" [8]. Secondly, self-organizing geosystems constantly generate new forms of mass and energy, which are then stored for future development needs. Hence, they represent economic resources for the society that employs them partially or totally (by destruction). Thus, geosystemic self-organization is the only source of production and reproduction of resources for the development of society in a finite geographical space. From this perspective, only the balanced exploitation of these resources through rational planning can give us the certainty of the perpetuation of human civilization. The overexploitation of resources could quickly lead to a generalized crisis and eventually to the collapse of the present civilization. This would disintegrate into small social fractions, which will be required to adjust the lower levels of social organization in line with the level of entropy and self-organization.

13). It is the main generator of negative entropy (negentropy) in the geographical space - the source of anthropogenic systems. The existence, functionality, organization and development of all categories of systems, including geo- and socioeconomic systems, are based on the existence of mass, energy and information, under various states and of different entropy levels. Any system fights to access mass and low-entropy free energy flows, which, once assimilated, would increase the internal order and self-organization. Therefore, the level of geosystemic self-organization is equivalent to the potential difference of flow and it is the product of entropy level existing in the geographical space at some point. Each type of geosystem is specialized in using inputs of mass and energy of a certain entropy level for their internal needs of self-organization and development, inputs always having lower entropy than outputs, according to the Second Law of Thermodynamics. We can thus acknowledge that there are geosystemic hierarchy levels, not only in size, structural complexity and function but also in terms of generated entropy. The entropy generated by higher ranked geosystems represents negentropy for any other lower ranked geosystems, resulting in systemic interdependence. Man-made systems are no exception to this rule, their place in this hierarchy being somewhere towards the bottom. Thus, if in the case of biological man the rank in the entropy hierarchy can be exactly determined, in the case of social and especially technological man we note a translation between entropy levels. Based on technology, man has got access to pure (nuclear) very low entropy level energy, or directly captures solar energy waste without being so dependent on geosystems, to partially meet their needs. Yet, man cannot disregard their biological traits, which are clearly defined in the entropy hierarchy. And this makes us be dependent on geosystems and learn to respect them since we depend on their generated entropy.

\section{CONCLUSION}

The capacity of matter to self-organize in the geographical space, thus generating a wide variety of objects, processes and phenomena is the key to understanding how people and society as a whole have adapted to the geographical space through spatial planning and organization. As biological entities, people represent biochemical energy dissipative systems and they try to fit into the biogeochemical circuits of substance and energy in the geographical space. While human needs are continuously multiplying and diversifying, people are adjusting their ability to dissipate energy within the geographical space. Thus, the more profound the perception on the self-organization, the more extensive and long- 
term benefits are. However, due to increasing energy needs of population, we can note clear adaptive measures taken to fulfil them, mostly negative, and sometimes severely affecting nature or permanently destroying some geosystems by exploiting natural resources to exhaustion. Thus, after some geosystemic dissipative structure is destroyed a certain amount of "free energy" is released in the geographical space, becoming a resource for other lower ranked geosystems. The ultimate aim of self-organization is to maintain thermodynamic equilibrium by dissipating most efficiently and completely that free and available energy. This proves that the harmonious integration of man into the structures of geosystems and assure its survival as a species in the geographical space depends firstly on meeting its own energy needs to ensure stability and order of man-made structures, and secondly on avoiding or eliminating jams in the energy flows to other geosystems, which can trigger reactions, namely positive feedbacks through the disruption of these structures, having space-time impact on the organization of other geosystems [5, p. 27]. Thus, the acknowledgment of self-organization of geosystems must be a preliminary step required in case of any human interventions in any geographic area prior to spatial planning actions. The design of anthropogenic structures consistent with state and self-organization parameters could indeed represent the prerequisite for the sustainable development of human society. Planning should not be pattern-driven but consistent with the selforganization pattern of natural systems due to their multiple variations. Not considering the natural course of the environment where sociosystems are implanted is a drawback in planning. Positive results of planning may be short-time, yet without assuring long-lasting effects without negative influence on the geosystems. In reverse, geosystems will eventually react against the sociosystems.

\section{REFERENCES}

[1] Hao Hua. Planning meets self-organization: Integrating interactive evolutionary computation with cellular automata for urban planning, Frontiers of Architectural Research (2012) 1, pp. 400-404.

[2] Barthelemy, M., Bordin, P., Berestycki, H., Gribaudi, M. Self-organization versus top-down planning in the evolution of a city. Sci. Rep. 3, 2153; (2013). pp. 1-7

[3] Juval Portugali (1999), Self-organization and the city, Springer-Verlag Berlin.

[4] Goleusov, P. V., 2014, The Concept of Renaturation of Anthropogenically Disturbed Geosystems: Methodological and Applied Aspects, Geographical Sciences,

Fundamental Research № 11, 2014, pp. 556-564.

[5] Zotic, Vasile. Componentele operaționale ale organizării spaţiului geografic, Presa Universitară Clujeană, Cluj-Napoca, Romania. 2006.

[6] Rejmers, N. Ohrana prirody i okružajuščej čeloveka sredy. Izd-vo Prosveščenie, Moskva. 1992.

[7] Pulselli M. Ricardo, Tiezzi Enzo. City out of Chaos. Urban Self-Organization and Sustainability. WIT Press, Southampton, Boston. 2009.

[8] Commoner, B. Cercul care se închide. Editura Politică, Bucureşti. 1980

[9] Allen M. Peter. Cities and Regions as Self-Organizing Systems. Models of Complexity, Taylor \& Francis, 2005, pp. 1-29.

[10] E.R. Alexander, Luigi Mazza, Stefano Moroni. Planning without plans? Nomocracy or teleocracy for social-spatial ordering. Progress in Planning 77 (2012) 37-87

[11] Beitske Boonstra, Luuk Boelens. Self-organization in urban development: towards a new perspective on spatial planning, Urban Research \& Practice, 4:2(2011), 99-122. 
Physical Geography; Cartography; Geographic Information Systems \& Spatial Planing 
International Scientific Conference GEOBALCANICA 2015 